\section{Morphological Characterization of Ficus religiosa Genotypes in Iran by Multivariate Analysis}

\author{
Mohsen Hesami \\ Department of Horticultural Sciences, Faculty of Agriculture, University of \\ Tehran, Karaj, Iran

\section{Mostafa Rahmati-Joneidabad ${ }^{1}$ \\ Department of Horticultural Science, Faculty of Agriculture, Khuzestan Agricultural Sciences and Natural Resources University, Mollasani, Iran}

Additional index words. bodhi, quantitative character, genetic resources, correlation coefficients, principal component analysis, cluster

\begin{abstract}
Ficus religiosa $\mathbf{L}$. is one of the most popular species in the Moraceae family that is known as a multipurpose forest tree species because of its medicinal, ornamental, and religious value. $F$. religiosa is an important tree in South Asia, and it possesses various common names such as peepal, bodhi, bo tree, and asvattha. This species as a traditional tree is broadly planted as a roadside tree, and it plays an important role as a medicinal tree in various diseases such as asthma, stomatitis, diabetes, inflammations, glandular swelling disorders, and wound healing. Because $F$. religiosa is characterized as a subtropical tree, it fully grew in southern parts of Iran. The morphological variation of 72 individuals of $F$. religiosa from six southern regions of Iran was investigated based on multivariate analysis. Our results indicated that the highest tree, leaf, and petiole lengths, as well as leaf width, were observed in Kish and Qeshm genotypes, whereas the Chabahar genotype had the lowest petiole length. Results of simple correlation analysis showed the existence of significant positive and negative correlations among some important parameters. The highest correlation was observed between leaf, tree, and petiole lengths. Populations were clustered in four groups. The Kish and Qeshm genotypes were closely related to each other and differentiated from the Chabahar genotype. The whole dataset was subjected to principal component analysis (PCA). PCA showed that the first two factor components explained $84.51 \%$ of the variation and the first factor component had the positive relationship with leaf, tree, and petiole lengths.
\end{abstract}

Ficus is the genus of 1000 species in the family Moraceae, mainly distributed throughout tropical and subtropical regions (Hesami and Daneshvar, 2018). Many of this species have ornamental value and are also used as medicinal plants. Ficus religiosa L. is a long-lived, large, fuel wood, medicinal, ornamental, and evergreen perennial tree with glossy green foliage, native to India, mainly found in Pakistan, Bangladesh, Ceylon, China, Burma, Thailand, and Iran (Hesami et al., 2017b; Hesami et al., 2018b; Singh et al., 2011). It is also known as a roadside tree and most frequently found near temples. Different parts of $F$. religiosa are extensively used in indigenous medicine, especially for their antibacterial (Pawar and Nabar, 2010), anticonvulsive (Patil et al., 2011), antidiabetic (Kirana et al., 2009), antinephropathic (Ballabh et al., 2008), wound healing (Ghosh et al., 2016), anti-inflammatory and analgesic

Received for publication 9 Mar. 2018. Accepted for publication 22 Apr. 2018.

${ }^{1}$ Corresponding author. E-mail: rahmati@ramin. ac.ir. and cluster analysis, are applicable means for screening individuals for many plants such as Cerasus subgenus (Khadivi-Khub et al., 2012), Prunus dulcis (Chalak et al., 2007), Origanum vulgare (Andi et al., 2011), and Punica granatum (Sarkhosh et al., 2009). Also, multivariate methods can help to assess large datasets and resolve various phenotypic and genotypic evaluations into fewer more interpretable and more easily visualized groups (Hesami et al., 2017c).

The feasible details about the diversity of morphological features within and among various subspecies of $F$. religiosa may be applied in the delimitation of subspecies and also it can be used in breeding programs and conservation of this valuable plant. Therefore, this article explains morphological variable of $F$. religiosa in different regions of Iran that also could apply to understanding the taxonomy of this valuable plant.

\section{Materials and Methods}

A total of 72 individuals of $F$. religiosa were studied in their natural habitats from six regions of southern parts of Iran (Fig. 1). Twelve plants were sampled randomly from each population. Sampling locations and their geographic coordinates are shown in Table 1 . The interval between samples was 300-500 $\mathrm{m}$, whereas the pairwise distance between main regions was $300-600 \mathrm{~km}$. The sampled stands were chosen to provide a maximum representation of the ecological conditions of the area.

The morphological study was conducted in Spring and Summer of 2016. Eight morphological traits were (flake thickness, fruit diameter, leaf length, leaf width, peduncle length, petiole length, tail-like tips, and tree length) evaluated in natural ecosystems. Morphological data were analyzed by SAS program for analysis of variance (ANOVA). Mean of values were compared using ANOVA and Duncan's multiple range test. The simple correlation coefficient was calculated to indicate the relationships between the studied traits, and PCA was performed using the SPSS software. Morphological characteristics were measured to evaluate the Euclidean distance between all pairs of individuals using the Signed module of NTSYS-pc software version 2.01. These distance coefficients were applied for constructing a dendrogram using the unweighted pair group method with arithmetic averages using the sequential, hierarchical, agglomerative, and nested clustering algorithm. Also, scatter plot of the first two meaningful principal components was created by PAST statistics software.

\section{Results and Discussion} genetic diversity among morphologically distinguishable individuals and their simple evaluation as well. Morphological features in accompany with multivariate statistical methods, such as PCA that was broadly used,
According to Table 2, the highest tree, leaf, and petiole lengths, as well as leaf width, were observed in Kish and Qeshm genotypes, 


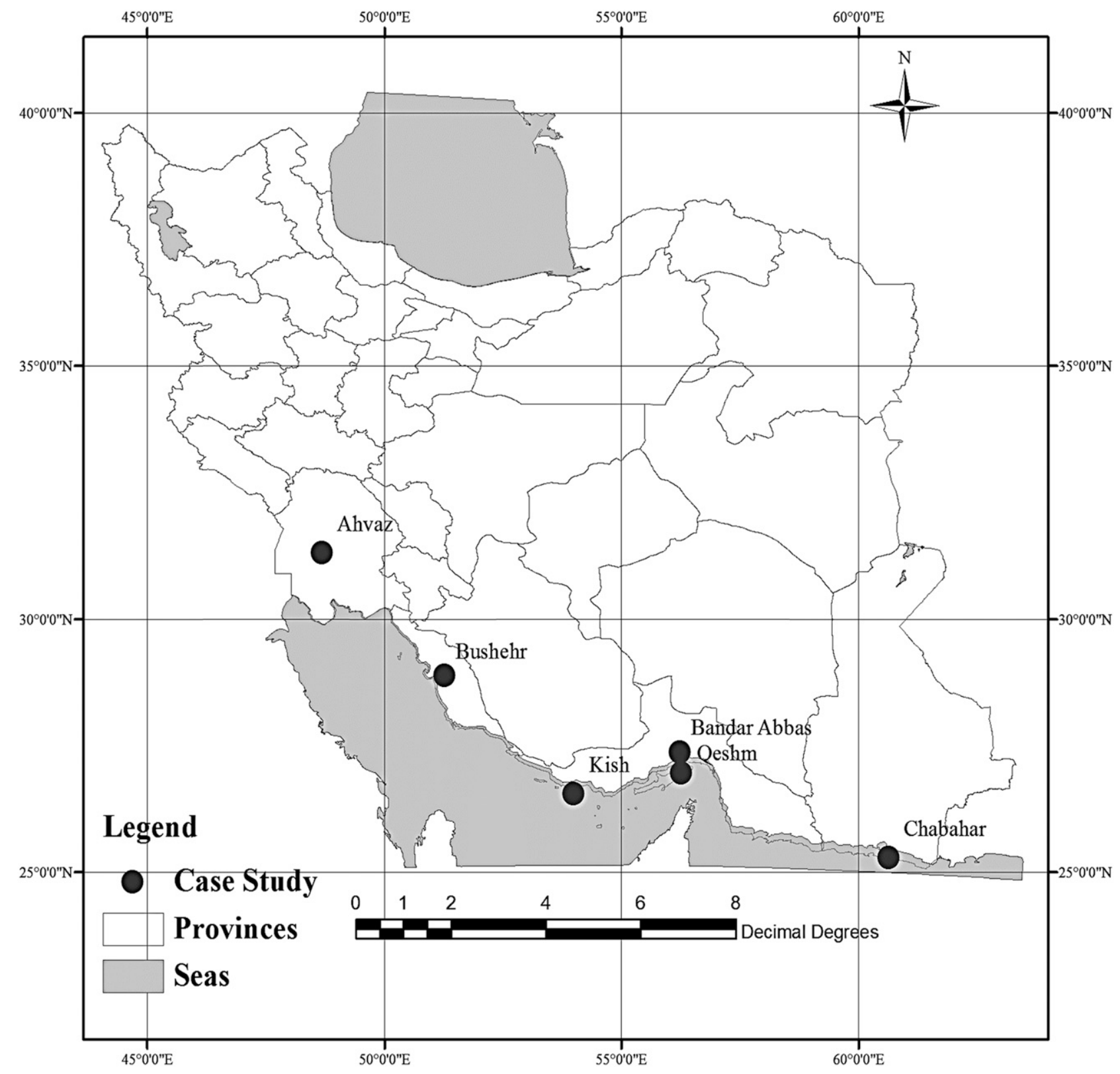

Fig. 1. Geographic location of selected sites of Ficus religiosa populations.

Table 1. Locations of studied Ficus religiosa genotypes.

\begin{tabular}{|c|c|c|c|c|c|c|c|}
\hline Genotypes & Province & Altitude (m) & $\begin{array}{c}\text { Longitude } \\
\text { (decimal degrees) }\end{array}$ & $\begin{array}{c}\text { Latitude } \\
\text { (decimal degrees) }\end{array}$ & Temperature $\left({ }^{\circ} \mathrm{C}\right)$ & Precipitation (mm) & $\begin{array}{c}\text { Relative } \\
\text { humidity (\%) }\end{array}$ \\
\hline Bandar Abbas & Hormozgan & 9.1 & $56.2808^{\circ} \mathrm{E}$ & $27.1865^{\circ} \mathrm{N}$ & 27.0 & 176.1 & 65 \\
\hline Bushehr & Bushehr & 8 & $50.8203^{\circ} \mathrm{E}$ & $28.9234^{\circ} \mathrm{N}$ & 24.7 & 268.0 & 65 \\
\hline Kish & Hormozgan & 32 & $53.9868^{\circ} \mathrm{E}$ & $26.5325^{\circ} \mathrm{N}$ & 27.1 & 169.6 & 60.6 \\
\hline Qeshm & Hormozgan & 10 & $55.8913^{\circ} \mathrm{E}$ & $26.8119^{\circ} \mathrm{N}$ & 27.0 & 141.9 & 63.1 \\
\hline
\end{tabular}

Table 2. Morphological traits of Ficus religiosa genotypes in different regions.

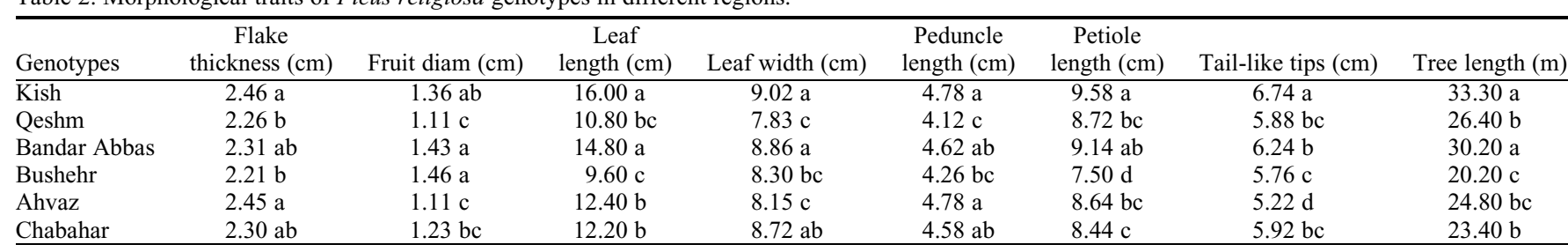

Means followed by the same letter within columns are not significantly different $(P=0.05)$ using Duncan's multiple range test. 

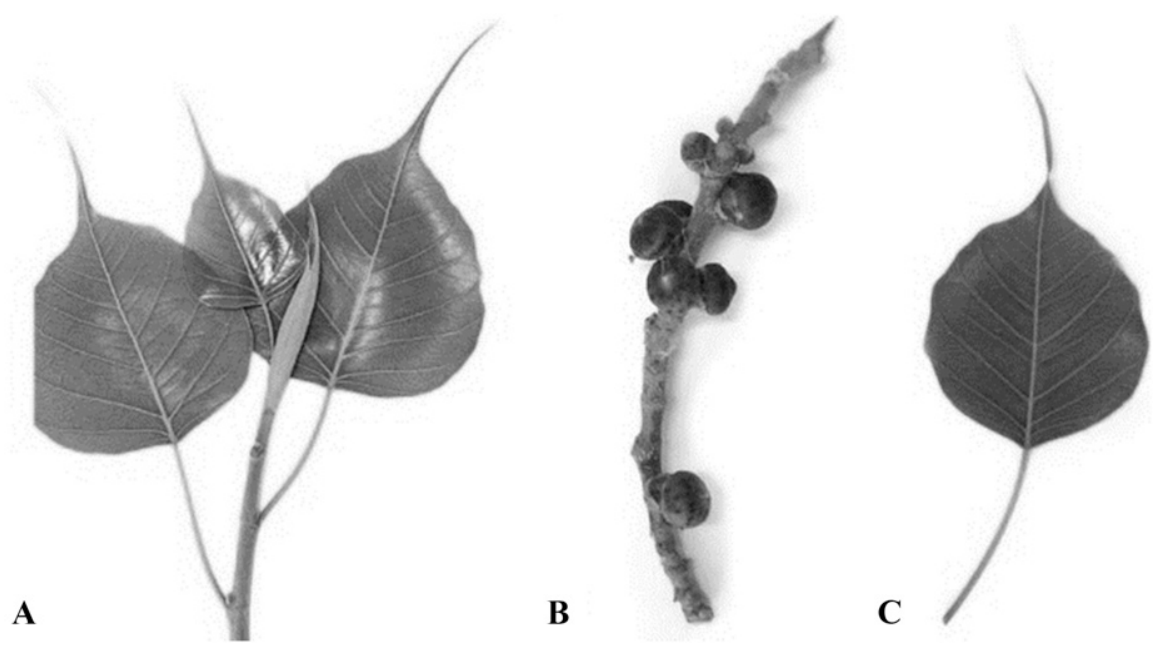

Fig. 2. Pictures of (A) leaves, (B) fruits, (C) petiole, and tail-like tips of Ficus religiosa in this study.

and also Chabahar genotype had the lowest petiole length (Fig. 2).

Results of simple correlation analysis (Table 3) showed the existence of significant positive and negative correlations among some important parameters. The highest correlation was observed between leaf, tree, and petiole length.

Populations were clustered in four groups (Fig. 3). The Kish and Qeshm genotypes were closely related with each other and differentiated from the Chabahar genotype. The highest distance was observed between the Kish and Chabahar genotypes (Fig. 3).

According to Table 4, PCA showed that the first two factor components explained $84.51 \%$ of the variation.

The first factor component had the positive relationship with leaf, tree, and petiole lengths and the second one had a negative effect with flake thickness, leaf length, peduncle, petiole, and tree lengths (Table 5).

These results have a high paramount to the success of a breeding program that mainly depends on the availability of a broad genetic base. Also, the maintaining of genetic diversity is one of the most important objectives in preserving endangered and threatened plants (Akbari et al., 2018; Ebrahimi et al., 2012a, 2012b; Farajpour et al., 2011; Hesami and Daneshvar, 2016a, 2016b; Khadivi-Khub et al., 2012). The knowledge of genetic diversity among populations gives some essential details in the formulation of suitable management strategies for preserving (Francisco-Ortega et al., 2000; Milligan et al., 1994). First, it should be prohibited to keep efficient population sizes because the population size is a critical restoration consideration in endangered plants (Allendorf, 1986). Cruse-Sanders et al. (2005) recommended that preserving a proportion of the individuals in populations is of high paramount to secure the evolutionary potential and reproductive fitness of the species. Second, the construction of an in situ preservation area is a perfect way to secure wild
$F$. religiosa genetic resources. It will result in the efficient preservation of their genetic resources and the evolution of the resources under natural conditions. Third, it is necessary to provide a long-term schedule to preserve existing natural populations to protect as much genetic diversity as possible. Fourth, ex situ preservation that mainly focused on seed harvest from various sources should be conducted to capture most of the genetic diversity existed among populations. As an important conventional medicinal plant, promoting domestication and cultivation of this wild resource is very essential both to satisfy market demand and secure the wild resource. Successful cultivation may decline the harvest of the wild genetic diversity of $F$. religiosa and contribute to the conservation of this important medical plant.

\section{Conclusions}

Iran has the national and international heritage of some valuable medicinal plants such as $F$. religiosa and it is necessary to schedule a long-term plan to identify and understand the growth habitat of this valuable plant. Our results indicated that the Qeshm and Kish genotypes of F. religiosa had the highest tree, leaf, and petiole lengths, as well as leaf width. Also, these two genotypes had a close relationship with each other in comparison with other genotypes. The simple correlation analysis indicated that the leaf, tree, and petiole lengths had the highest positive correlation with each other. Overall, it seems that the Kish and Qeshm genotypes had a high similarity to each other and they had a significant difference with the Chabahar genotype. The feasible details about the diversity of morphological features within and among various subspecies of $F$. religiosa may be applied in the delimitation of subspecies and also it can be used in breeding programs and conservation of this valuable plant.

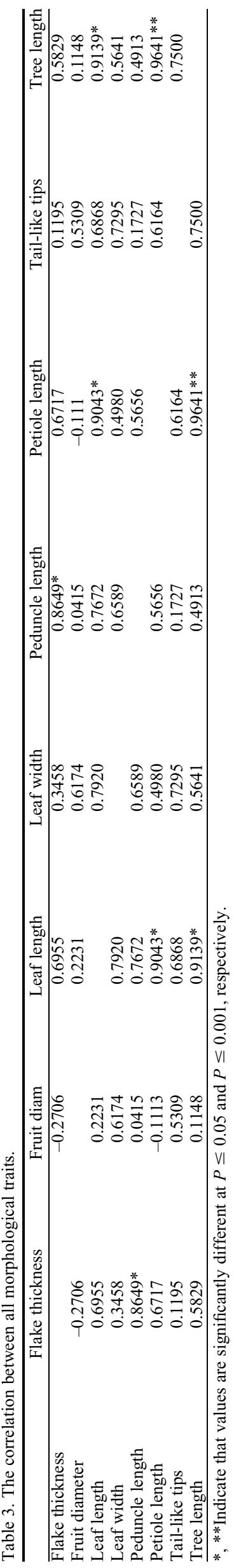

HortScience Vol. 53(7) July 2018 
Dendrogram

Ward's Method,Squared Euclidean

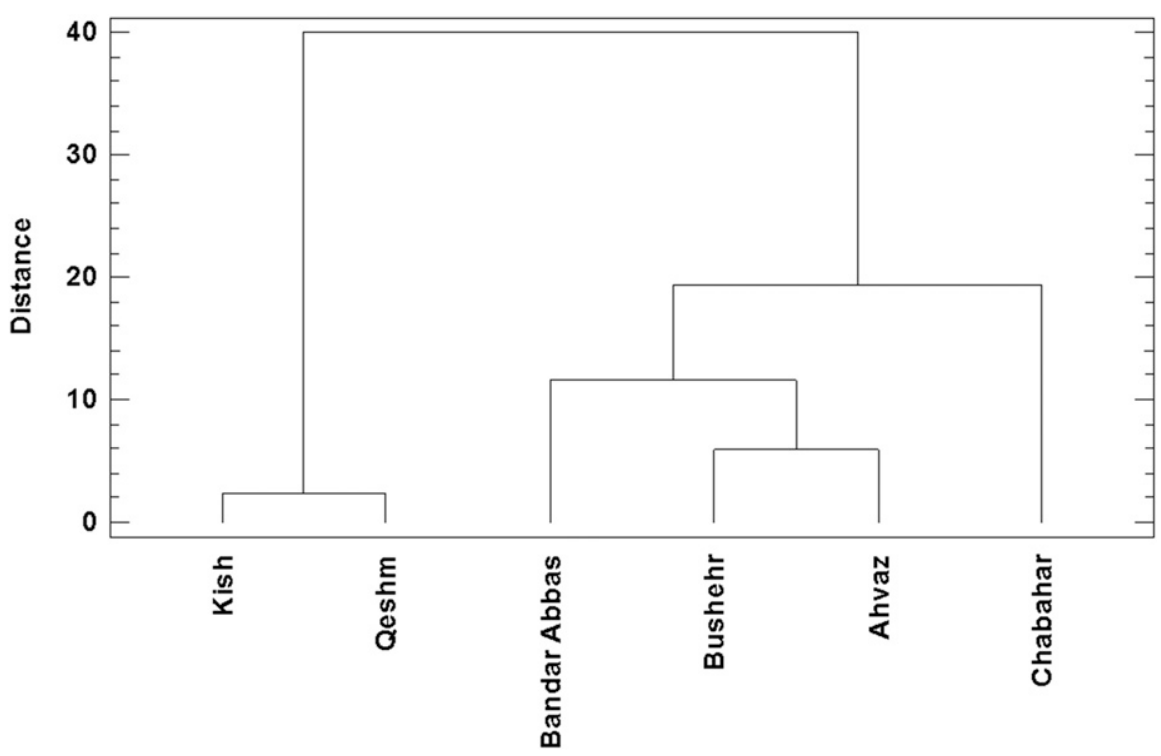

Fig. 3. The cluster analysis of six genotypes of Ficus religiosa L.

Table 4. Principal component analysis of morphological traits.

\begin{tabular}{lccc}
\hline $\begin{array}{l}\text { Component } \\
\text { no. }\end{array}$ & Eigenvalue & $\begin{array}{c}\text { Percent of } \\
\text { variance }\end{array}$ & $\begin{array}{c}\text { Cumulative } \\
\text { percentage }\end{array}$ \\
\hline 1 & 4.92994 & 61.624 & 61.624 \\
2 & 1.83104 & 22.888 & 84.512 \\
3 & 0.955183 & 11.940 & 96.452 \\
\hline
\end{tabular}

Table 5. Components weight of morphological traits.

\begin{tabular}{lcc}
\hline Traits & Component 1 & Component 2 \\
\hline Flake thickness & 0.318669 & -0.457801 \\
Fruit diameter & 0.1089 & 0.650876 \\
Leaf length & 0.447711 & -0.0167795 \\
Leaf width & 0.363317 & 0.316454 \\
Peduncle length & 0.343079 & -0.255207 \\
Petiole length & 0.401719 & -0.177167 \\
Tail-like tips & 0.326494 & 0.411636 \\
Tree length & 0.410447 & -0.0197917 \\
\hline
\end{tabular}

\section{Literature Cited}

Akbari, M., M. Farajpour, M. Aalifar, and M. Sadat Hosseini. 2018. Gamma irradiation affects the total phenol, anthocyanin and antioxidant properties in three different Persian pistachio nuts. Nat. Prod. Res. 32:322-326.

Allendorf, F.W. 1986. Genetic drift and the loss of alleles versus heterozygosity. Zoo Biol. 5:181190.

Andi, S., V. Nazeri, Z. Zamani, and J. Hadian. 2011. Morphological diversity of wild Origanum vulgare (Lamiaceae) in Iran. Iran. J. Bot. 17:211-221.

Ballabh, B., O. Chaurasia, Z. Ahmed, and S.B. Singh. 2008. Traditional medicinal plants of cold desert Ladakh-used against kidney and urinary disorders. J. Ethnopharmacol. 118:331339.

Bhangale, J.O., N.S. Acharya, and S.R. Acharya 2016. Protective effect of Ficus religiosa (L.) against 3-nitropropionic acid induced Huntington disease. Orient. Pharm. Expt. Med. 16:165-174.
Cagno, V., A. Civra, R. Kumar, S. Pradhan, M. Donalisio, B.N. Sinha, M. Ghosh, and D. Lembo. 2015. Ficus religiosa L. bark extracts inhibit human rhinovirus and respiratory syncytial virus infection in vitro. J. Ethnopharmacol. 176:252-257.

Chalak, L., A. Chehade, and A. Kadri. 2007. Morphological characterization of cultivated almonds in Lebanon. Fruits 62:177-186.

Cruse-Sanders, J.M., J. Hamrick, and J.A. Ahumada. 2005. Consequences of harvesting for genetic diversity in American ginseng (Panax quinquefolius L.): A simulation study. Biodivers. Conserv. 14:493-504.

Dwivedi, P., S.S. Narvi, and R.P. Tewari. 2014 Phytofabrication characterization and comparative analysis of $\mathrm{Ag}$ nanoparticles by diverse biochemicals from Elaeocarpus ganitrus Roxb., Terminalia arjuna Roxb., Pseudotsuga menzietii, Prosopis spicigera, Ficus religiosa Ocimum sanctum, Curcuma longa. Ind. Crops Prod. 54:22-31.

Ebrahimi, M., M. Farajpour, H. Hadavand, K. Bahmani, and F. Khodaiyan. 2012a. Essential oil variation among five Achillea millefolium ssp. elbursensis collected from different ecological regions of Iran. Ann. Biol. Res. 3:32483253.

Ebrahimi, M., M. Farajpour, and M. Rahimmalek. $2012 \mathrm{~b}$. Inter-and intra-specific genetic diversity of Iranian yarrow species Achillea santolina and Achillea tenuifolia based on ISSR and RAPD markers. Genet. Mol. Res. 11:28552861.

Farajpour, M., M. Ebrahimi, R. Amiri, S. Noori, S. Sanjari, and R. Golzari. 2011. Study of genetic variation in yarrow using inter-simple sequence repeat (ISSR) and random amplified polymorphic DNA (RAPD) markers. Afr. J. Biotechnol. 10:11137-11141

Ferrer-Gallego, P.P., F. Boisset, and G.K. Upadhyay. 2016. Lectotypification of the name of the sacred tree Ficus religiosa (Moraceae). Taxon 65:158-162.

Francisco-Ortega, J., A. Santos-Guerra, S.-C. Kim, and D.J. Crawford. 2000. Plant genetic diversity in the Canary Islands: A conservation perspective. Amer. J. Bot. 87:909-919.

Ghosh, M., A. Civra, M. Rittà, V. Cagno, S.G Mavuduru, P. Awasthi, D. Lembo, and M. Donalisio. 2016. Ficus religiosa L. bark extracts inhibit infection by herpes simplex virus type 2 in vitro. Arch. Virol. 161:3509-3514.

Hesami, M. and M.H. Daneshvar. 2016a. Development of a regeneration protocol through indirect organogenesis in Chenopodium quino Wild. Indo-Amer. J. Agr. Vet. Sci. 4:25-32.

Hesami, M. and M.H. Daneshvar. 2016b. Regeneration from callus which is produced from cotyledon of Antirrhinum majus. Indo-Amer. J. Agr. Vet. Sci. 4:20-24.

Hesami, M. and M.H. Daneshvar. 2018. In vitro adventitious shoot regeneration through direct and indirect organogenesis from seedlingderived hypocotyl segments of Ficus religiosa L.: An important medicinal plant. HortScience 53:55-61.

Hesami, M., M.H. Daneshvar, and A. Lotfi. 2017a. In vitro shoot proliferation through cotyledonary node and shoot tip explants of Ficus religiosa L. Plant Tissue Cult. Biotechnol. 27:85-88.

Hesami, M., M.H. Daneshvar, and M. YoosefzadehNajafabadi. 2018a. An efficient in vitro shoo regeneration through direct organogenesis from seedling-derived petiole and leaf segments and acclimatization of Ficus religiosa. J. For. Res. doi: 10.1007/s11676-11018-10647-11670.

Hesami, M., M.H. Daneshvar, and M. YoosefzadehNajafabadi. 2018b. Establishment of a protocol for in vitro seed germination and callus formation of Ficus religiosa L., an important medicinal plant. Jundishapur J. Nat. Pharm. Prod. 13: e62682.

Hesami, M., M.H. Daneshvar, M. YoosefzadehNajafabadi, and M. Alizadeh. 2017b. Effect of plant growth regulators on indirect shoot organogenesis of Ficus religiosa through seedling derived petiole segments. J. Gen. Eng Biotech. 16:175-180.

Hesami, M., R. Naderi, M. Yoosefzadeh-Najafabadi, and M. Rahmati. 2017c. Data-driven modeling in plant tissue culture. J. Appl. Environ. Biol. Sci. 7:37-44

Keshari, A.K., G. Kumar, P.S. Kushwaha, M Bhardwaj, P. Kumar, A. Rawat, D. Kumar, A. Prakash, B. Ghosh, and S. Saha. 2016. Isolated flavonoids from Ficus racemosa stem bark possess antidiabetic, hypolipidemic and protective effects in albino Wistar rats. J. Ethnopharmacol. 181:252-262.

Khadivi-Khub, A., Z. Zamani, and M.R. Fatahi. 2012. Multivariate analysis of Prunus subgen. Cerasus germplasm in Iran using morphological variables. Genet. Resources Crop Evol 59:909-926.

Kirana, H., S. Agrawal, and B. Srinivasan. 2009. Aqueous extract of Ficus religiosa Linn. reduces oxidative stress in experimentally induced type 2 diabetic rats. Indian J. Expt. Biol. 47:822826

Mallurwar, V. and A. Pathak. 2008. Studies on immunomodulatory activity of Ficus religiosa. Indian J. Pharm. Educ. Res. 42:341-343.

Milligan, B.G., J. Leebens-Mack, and A. Strand. 1994. Conservation genetics: Beyond the maintenance of marker diversity. Mol. Ecol $3: 423-435$.

Pandit, R., A. Phadke, and A. Jagtap. 2010 Antidiabetic effect of Ficus religiosa extract in streptozotocin-induced diabetic rats. J. Ethnopharmacol. 128:462-466.

Patil, M.S., C. Patil, S. Patil, and R. Jadhav. 2011. Anticonvulsant activity of aqueous root 
extract of Ficus religiosa. J. Ethnopharmacol. 133:92-96.

Pawar, P.L. and B.M. Nabar. 2010. Effect of plant extracts formulated in different ointment bases on MDR strains. Indian J. Pharm. Sci. 72:397401.

Salmi, M.S. and M. Hesami. 2016. Time of collection, cutting ages, auxin types and concentrations influence rooting Ficus religiosa L. stem cuttings. J. Appl. Environ. Biol. Sci. 6:124-132.
Sankar, R., R. Maheswari, S. Karthik, K.S. Shivashangari, and V. Ravikumar. 2014. Anticancer activity of Ficus religiosa engineered copper oxide nanoparticles. Mater. Sci. Eng. C Mater. Biol. Appl. 44:234-239.

Sarkhosh, A., Z. Zamani, R. Fatahi, and H. Ranjbar. 2009. Evaluation of genetic diversity among Iranian soft-seed pomegranate accessions by fruit characteristics and RAPD markers. Scientia Hort. 121:313-319.
Singh, D., B. Singh, and R.K. Goel. 2011. Traditional uses, phytochemistry and pharmacology of Ficus religiosa: A review. J. Ethnopharmacol. 134:565-583.

Vinutha, B., D. Prashanth, K. Salma, S. Sreeja, D. Pratiti, R. Padmaja, S. Radhika, A. Amit, K. Venkateshwarlu, and M. Deepak. 2007. Screening of selected Indian medicinal plants for acetylcholinesterase inhibitory activity. J. Ethnopharmacol. 109:359-363. 